\title{
Hubungan Antara Kecerdasan Moral dengan Kecerdasan Sosial Siswa SD Kelas IV Gugus XII Kota Bengkulu
}

\author{
Nada Suherli \\ Universitas Bengkulu \\ nadasuherly@gmail.com \\ Herman Lusa \\ Universitas Bengkulu \\ hermandatuk1005@gmail.com \\ Neza Agusdianita \\ Universitas Bengkulu \\ neza.agusdianita@gmail.com
}

\begin{abstract}
This study aims to determine the relationship between moral intelligence and social intelligence of elementary school students Class IV XII Bengkulu City. This type of research is quantitative research using correlational research method. The population in this study all elementary school students Gugus XII Bengkulu City as much as 4 elementary school with 240 students. The sample in this study were 34 students taken proportionately. Data collection techniques and instruments in this study using a questionnaire. Data analysis technique using product moment correlation formula and t test. The results of this study indicate that the value of $r$ hitung $=0.471$ is greater than $r$ tabel $=$ 0.339 , with contribution percent $22.17 \%$ and at significant level ( $t$ hitung) 3.019 which means Ha accepted. Thus it can be concluded that there is a relationship between moral intelligence and social intelligence of elementary school students in grade IV XII of Bengkulu City.
\end{abstract}

Keywords: Moral Intelligence, Social Intelligence.

\begin{abstract}
Abstrak
Penelitian ini bertujuan untuk mengetahui hubungan antara kecerdasan moral dan kecerdasan sosial siswa sekolah dasar Kelas IV XII Kota Bengkulu. Jenis penelitian ini adalah penelitian kuantitatif dengan menggunakan metode penelitian korelasional. Populasi dalam penelitian ini adalah semua siswa sekolah dasar Gugus XII Kota Bengkulu sebanyak 4 sekolah dasar dengan 240 siswa. Sampel dalam penelitian ini adalah 34 siswa yang diambil secara proporsional. Teknik pengumpulan data dan instrumen dalam penelitian ini menggunakan kuesioner. Teknik analisis data menggunakan rumus korelasi product moment dan uji t. Hasil penelitian ini menunjukkan bahwa nilai $r$ hitung $=0,471$ lebih besar dari $r$ tabel $=0,339$, dengan kontribusi persen $22,17 \%$ dan pada taraf signifikan (t hitung) 3,019 yang berarti $\mathrm{Ha}$ diterima. Dengan demikian dapat disimpulkan bahwa ada hubungan
\end{abstract}


antara kecerdasan moral dan kecerdasan sosial siswa sekolah dasar kelas IV XII Kota Bengkulu.

Kata kunci: Kecerdasan Moral, Kecerdasan Sosial.

\section{Pendahuluan}

Moral merupakan perilaku manusia yang berhubungan tentang benar atau pun salah dalam diri individu. Moral dilandasi dengan nilai-nilai yang diyakini oleh seseorang atau kelompok tertentu sebagai sesuatu yang baik atau buruk, sehingga dapat membedakan mana yang harus dilakukan dan mana yang tidak harus dilakukan.

Moral terkait dengan proses sosialisasi individu anak, jika manusia tanpa moral maka tidak bisa melakukan proses sosialisasi. Moral juga menjadi sifat dasar yang diajarkan baik di sekolah maupun tempat tinggal dan anak juga harus mempunyai moral jika ingin dihormati oleh sesama. Drajat (2014: 15) mengatakan bahwa manusia harus hidup dan berbuat baik agar menjadi manusia yang baik, sehingga dibutuhkan sistem nilai atau konsensus sosial tentang perilaku, motivasi, dan perbuatan yang dinilai baik atau buruknya.

Sejauh ini kekhawatiran terbesar adalah tindak kekerasan yang dilakukan anakanak sehingga perlu segera diatasi. Beberapa bulan sebelumnya, terdapat berita tentang siswa SD tewas usai berkelahi dengan temannya. Siswa AR SDN 5 Ciapus 2 Banjaran, Kabupaten Bandung, Jawa Barat yang tewas usai berkelahi dengan AM. Penyebab perkelahian tersebut didasari oleh permasalahan sepele yaitu ketika korban menyetel motor bising dan menganggu pelaku (detiknews, 2017). Hal ini memperlihatkan bahwa moral diatur dengan segala perbuatan yang dinilai baik dan perlu dilakukan, dan suatu perbuatan yang dinilai tidak baik dan harus dihindari. Sehingga moral berkaitan dengan kemampuan untuk membedakan antara perbuatan yang baik dan perbuatan yang buruk. Kemampuan yang berkaitan dengan moral tersebut yaitu kecerdasan moral.

Kecerdasan moral merupakan kemampuan dalam memahami hal yang benar dan hal yang salah. Kita tumbuh secara moral yaitu untuk mengetahui bagaimana bersikap terhadap orang lain, bagaimana berperilaku yang baik di sekolah maupun tempat tinggal. Anak yang mempunyai perilaku baik dan dapat menjaga perasaan orang lain akan memiliki kecerdasan moral yang tinggi. Hasil penelitian Notosrijoedono (2015: 13) menyimpulkan bahwa "Anak yang mempunyai kecerdasan moral yang tinggi biasanya mampu mengatasi persoalan yang dihadapinya dengan baik, anak jika menghadapi masalah akan dengan cepat berpikir bagaimana pemecahan masalahnya, semua pekerjaan akan dijadwal dengan baik sehingga terlihat tertib, rapih, rajin dalam melaksanakan tugas-tugas yang diberikan kepadanya dan mampu menjaga perasaan orang lain". Sehingga kecerdasan moral sangatlah penting untuk siswa SD di lingkungan sekolah dan lingkungan tempat tinggal.

Membangun kecerdasan moral sangatlah penting untuk siswa SD agar melindungi kehidupan moralnya sekarang dan selamanya. Dengan meningkatkan kecerdasan moral siswa SD, mereka tidak hanya berpikir dengan benar tetapi juga bertindak dengan benar dan terbangunnya karakter yang kuat (Borba, 2008: 4). Kecerdasan moral yang sangat penting ini merupakan kemampuan untuk memahami penderitaan orang lain dan tidak bertindak jahat, mendengarkan pendapat sebelum memberikan penilaian, dapat berempati dan menghargai perbedaan. Apabila anak telah melakukannya maka akan membentuk anak menjadi baik hati, berkarakter kuat dan warga negara yang baik. 
Dengan demikian, pendidikan yang baik bukan hanya membentuk siswa memiliki kecerdasan otak saja, melainkan harus membentuk siswa memiliki kecerdasan moral yang baik pula, yang dapat dilakukan dengan memberikan contoh teladan yang baik, penyuluhan serta bimbingan. Hal ini diperkuat oleh Coles (2003: 6-7) menyatakan kecerdasan moral dalam rasa hormatnya terhadap orang lain maupun terhadap dirinya sendiri. Kesadaran mendalam mengenai keterkaitan manusiawi. Prinsip-prinsip dasar moral yaitu tingkah laku, cara bergaul dengan orang lain sehingga dilakukan oleh setiap siswa.

Cara bergaul dengan orang lain sangatlah penting pada siswa SD. Apabila siswa mempunyai cara bergaul yang baik, maka akan mempunyai moral yang baik, kecerdasan intelektual yang baik dan kecerdasan sosial yang baik. Sehingga kecerdasan sosial yang baik perlu ditanamkan kepada diri anak terutama dalam kehidupan sehari-hari. Azzet (2014: 12-13) menyatakan bahwa kecerdasan sosial pada anak untuk terus dikembangkan agar kelak anak-anak mampu hidup secara sosial dengan baik. Seseorang yang mempunyai kecerdasan sosial yang baik akan mempunyai banyak teman, pandai berbicara, mudah beradaptasi dalam lingkungan sosial dan bermanfaat tidak hanya untuk dirinya sendiri tetapi juga orang lain. Apabila kecerdasan sosial ini tidak diterapkan dengan baik akan mempunyai dampak seperti minder dalam pergaulan, kurang diterima di lingkungan sosialnya karena sombong terhadap orang lain, dan tidak bisa menjalin hubungan sosial dengan baik. Kecerdasan sosial menjadi penting untuk diterapkan dalam kehidupan sehari-hari.

Kecerdasan sosial menjadi penting karena berhubungan sosial dengan orang lain. Hasil penelitian Afrianti (2015: 40) menyimpulkan bahwa kecerdasan sosial menjadi penting karena pada dasarnya manusia tidak dapat hidup sendiri. Banyak kegiatan dalam hidup terkait dengan orang lain. Individu yang gagal mengembangkan kecerdasan sosialnya akan mengalami banyak hambatan dalam dunia sosial. Akibatnya mereka mudah tersisihkan dalam lingkungan sosial. Sehingga individu menjadi kesepian, merasa tidak berharga, dan mengisolasi diri. pada akhirnya menyebabkan individu mudah depresi dan kehilangan kebermaknaan hidup. Individu yang terbatas pergaulan sosialnya akan banyak mengalami hambatan ketika memasuki lingkungan yang lebih luas seperti sekolah atau masyarakat. Apabila masalah sosial dibiarkan, akan membahayakan dalam penerimaan sosial oleh kelompok. Semakin jauh individu berada di bawah harapan sosial akan semakin merugikan penyesuaian pribadi dan sosial serta semakin buruk interaksi yang terjadi.

Berdasarkan pendapat di atas memberi indikasi bahwa kecerdasan moral mempunyai pengaruh yang besar terhadap kecerdasan sosial anak. Moral terbangun berdasarkan cinta. Apabila kita membangun ikatan dengan anak berdasarkan kasih sayang dan cinta, kita dapat memengaruhi mereka. Borba (2008: 4) menyatakan bahwa apabila ingin berhasil membuat anak-anak tidak hanya berpikir, tetapi juga bertindak sesuai dengan norma-norma moralitas; dan apabila anak tidak tahu bagaimana harus bertindak, perkembangan moral anak akan terganggu. Karakter dapat dilihat dari tindakan bukan hanya dari pemikiran.

Apabila moral anak terganggu akan berdampak dengan pergaulannya. Anak yang moralitasnya kurang bagus, maka akan dijauhi oleh teman. Sehingga sosialisasi anak tersebut mengalami keterbatasan. Anak yang mengalami keterbatasan sosial akan menjadi kesepian, merasa tidak berharga dan menjauhkan diri dari temantemannya. Sehingga, kecerdasan sosial menjadi penting dalam kehidupan seharihari.

Menurut Azzet (2014: 13) kecerdasan sosial anak menjadi penting karena seseorang yang mempunyai kecerdasan sosial yang baik akan mempunyai banyak teman, 
pandai dalam berkomunikasi, mudah beradaptasi pada lingkungan sosial dan bermanfaat untuk orang lain.

Oleh karena itu, untuk melihat secara faktual di lapangan, peneliti melakukan penelitian mengenai "Hubungan Antara Kecerdasan Moral dengan Kecerdasan Sosial Siswa SD kelas IV Gugus XII Kota Bengkulu”.

\section{Metode}

Jenis penelitian yang dapat digunakan adalah penelitian kuantitatif dengan metode korelasi. Metode penelitian yang digunakan adalah korelasi. Dalam penelitian ini menggunakan angket yang telah divalidasi oleh dosen psikologi.

Populasi dalam penelitian ini adalah seluruh siswa SD Kelas IV Gugus XII yang berjumlah 4 SD yaitu SD Negeri 20, SD Negeri 60, SD Negeri 81 dan SD Negeri 99 berakreditasi A Kota Bengkulu dan populasi berjumlah 240 siswa. Siswa kelas IV SD Negeri 20 berjumlah 108 siswa, siswa kelas IV SD Negeri 60 berjumlah 54 siswa, siswa kelas IV SD Negeri 81 berjumlah 44 siswa, dan siswa kelas IV SD Negeri 99 berjumlah 34 siswa.

Sampel yang digunakan pada penelitian ini menggunakan teknik simple random atau sampel acak. Peneliti mengambil sampel sebanyak $15 \%$ dari populasi secara random (acak). Populasi pada penelitian ini sebanyak 240 responden. Maka diperoleh sampel $15 \%$ x $240=34$ orang siswa.

Tabel 1. Tabel proposional sampel

\begin{tabular}{|c|c|c|c|c|c|c|c|}
\hline No & $\begin{array}{r}\mathrm{Se} \\
\mathrm{Gu} \\
\mathrm{Akr}\end{array}$ & $\begin{array}{l}\text { olah } \\
\text { us XII } \\
\text { ditasi } \\
\text { A }\end{array}$ & Kelas & Populasi & Perhitungan & $\begin{array}{l}\text { Jumlah } \\
\text { Sampel }\end{array}$ & $\begin{array}{c}\text { Sampel } \\
\text { Pembulatan }\end{array}$ \\
\hline \multirow[t]{3}{*}{1.} & \multirow[t]{3}{*}{$\begin{array}{l}\text { SD } \\
20\end{array}$} & \multirow[t]{3}{*}{ Negeri } & IV A & 36 & $\frac{36}{240} \times 36$ & 5,4 & 5 \\
\hline & & & IV B & 35 & $\frac{35}{240} \times 36$ & 5,2 & 5 \\
\hline & & & IV C & 37 & $\frac{37}{240} \times 36$ & 5,5 & 5 \\
\hline \multirow[t]{2}{*}{2} & \multirow[t]{2}{*}{$\begin{array}{l}\mathrm{SD} \\
60\end{array}$} & \multirow[t]{2}{*}{ Negeri } & IV A & 27 & $\frac{27}{240} \times 36$ & 4,0 & 4 \\
\hline & & & IV B & 27 & $\frac{27}{240} \times 36$ & 4,0 & 4 \\
\hline \multirow[t]{2}{*}{3} & \multirow[t]{2}{*}{$\begin{array}{l}\text { SD } \\
81\end{array}$} & \multirow[t]{2}{*}{ Negeri } & IV A & 23 & $\frac{23}{240} \times 36$ & 3,4 & 3 \\
\hline & & & IV B & 21 & $\frac{21}{240} \times 36$ & 3,1 & 3 \\
\hline 4 & $\begin{array}{l}\text { SD } \\
99\end{array}$ & Negeri & IV A & 34 & $\frac{34}{240} \times 36$ & 5,1 & 5 \\
\hline \multicolumn{3}{|c|}{ JUMLAH } & 240 & & & & 34 \\
\hline
\end{tabular}

Instrumen dalam penelitian ini menggunakan skala likert dalam bentuk angket dengan 20 pernyataan, responnya sebanyak 4 yaitu SS, S, KS TS. Lembar skala likert disusun sendiri oleh peneliti. Lembar skala likert divalidasi ahlioleh ahli psikologi dan diuji coba ke lapangan.Kemudia lembar skala likert diuji validitas dan uji reliabilitas. Hasil uji reliabilitas kecerdasan moral sebesar 0,90 dan reliabilitas sebesar 0,77 berarti instrumen ini valid dan reliabel.

Teknik pengumpulan data pada penelitian ini menggunakan angket atau kuesioner. Sumber datanya yaitu seluruh sampel dimana seluruh sampel akan mengisi lembar 
angket yang diberikan dengan memberi tanda checklist pada kolom yang telah disediakan.

Data dari penelitian ini dianalisis menggunakan analisis deskriptif dengan perhitungan mean dan varian, uji prasyarat dengan uji normalitas dan uji homogenitas, dan analisis inferensial dengan uji t.

\section{Hasil}

Tabel 2. Kecerdasan Moral dan Kecerdasan Sosial siswa kelas 4 SD Gugus XII Kota Bengkulu

\begin{tabular}{ccc}
\hline Deskripsi & $\begin{array}{c}\text { Kecerdasan } \\
\text { Moral }\end{array}$ & Kecerdasan Sosial \\
\hline Nilai Tertinggi & 68 & 61 \\
Nilai Terendah & 42 & 48 \\
\hline Jumlah Nilai & 1965 & 1874 \\
\hline Rata-rata & 57,79 & 55,12 \\
\hline Standar Deviasi & 6,75 & 4,07 \\
\hline Varian & 7,06 & 4,12 \\
\hline$x^{2}$ hitung & 11,78 & 9,82 \\
\hline$F_{\text {hitung }}$ & & \\
\hline$t_{\text {hitung }}$ & 3,019 \\
\hline
\end{tabular}

Berdasarkan hasil Tabel 2, hasil penelitian kecerdasan moral memiliki rata-rata 57,79 dan kecerdasan sosial memiliki rata-rata 55,12. Penelitian ini menggunakan uji prasyarat yaitu uji normalitas dan uji homogenitas.

Hasil uji normalitas disajikan pada Tabel 1 dimana nilai $x^{2}{ }_{\text {nitung }}$ keceradasan moral sebesar 11,78 dan kecerdasan sosial sebesar 9,82. Nilai $x^{2}$ tabel pada taraf signifikan $5 \%$ sebesar 12,59. Apabila $x^{2}{ }_{\text {hitung }}<x^{2}$ tabel maka data berdistribusi normal. Berdasarkan penjelasan di atas, hal ini berarti kedua data kecerdasan moral dan kecerdasan sosial siswa SD kelas IV Gugus XII Kota Bengkulu berdistribusi normal.

Hasil uji homogenitas disajikan pada Tabel 1 menunjukkan bahwa nilai $f_{\text {hitung }}$ sebesar 1,71 lebih kecil daripada nilai $f_{\text {tabel }}$ pada taraf signifikan $5 \%$ sebesar 1,80. Apabila $f_{\text {hitung }}<f_{\text {tabel }}$ maka data homogen. Dengan demikian dapat dikatakan bahwa data kecerdasan moral dan data kecerdasan sosial di SD Gugus XII Kota Bengkulu homogen.

Dari perhitungan didapatkan data normal dan homogen sehingga selanjutnya dilakukan perhitungan dengan uji-t. Berdasarkan Tabel 1 di atas dapat dilihat bahwa nilai hasil perhitungan uji t menunjukkan nilai $t_{\text {hitung }}$ sebesar 3,019 dan nilai $t_{\text {tabel }}$ pada taraf signifikan 5\% sebesar 1,668. Jika rhitung $\geq$ rtabel maka hipotesis alternatif (Ha) diterima. Maka dapat disimpulkan bahwa terdapat hubungan antara kecerdasan moral dengan kecerdasan sosial siswa SD Kelas IV gugus XII Kota Bengkulu.

\section{Pembahasan}

Pada penelitian ini, untuk menguji hipotesis maka peneliti menyebarkan angket kecerdasan moral dan angket kecerdasan sosial seluruh siswa SD Kelas IV Gugus XII Kota Bengkulu sebanyak 34 responden. Kemudian peneliti menganalisis ke dalam tabel kemudian dilakukan uji hipotesis dengan menggunakan rumus korelasi Product Moment. Diperoleh nilai $r_{\text {hitung }}$ adalah 0,471 dan $r_{\text {tabel }}$ 0,339, yang berarti terdapat hubungan kecerdasan moral dengan kecerdasan sosial siswa SD Kelas IV Gugus XII Kota Bengkulu. Selain itu, kecerdasan moral memberikan sumbangan sebesar $22,17 \%$ terhadap kecerdasan sosial. 
Dari besarnya sumbangan yang diberikan dan dengan korelasi yang cukup sebesar 0,471 ini membuktikan bahwa adanya korelasi yang cukup antara kecerdasan moral dengan kecerdasan sosial. Hal ini sejalan dengan pendapat Coles (2003: 5) "kecerdasan moral mempelajari bagaimana bersikap terhadap orang lain dan bagaimana berperilaku terhadap orang lain". Kecerdasan moral erat hubungannya dengan kecerdasan sosial yaitu dengan cara bagaimana anak melihat lingkungannya dan berinteraksi dengan teman sebaya.

Anak yang memiliki kecerdasan sosial yang baik akan mampu memahami perasaan orang lain, menerima orang lain apa adanya, serta mampu beradaptasi dengan orang lain. Apabila anak tidak memiliki kecerdasan sosial yang baik maka akan berdampak terhadap pergaulan di lingkungan sekolah maupun tempat tinggal. Sehingga kecerdasan sosial sangat penting untuk anak agar mempunyai kecerdasan sosial yang baik. Menurut Afrianti (2015: 40), "kecerdasan sosial menjadi penting karena pada dasarnya, seseorang tidak dapat hidup sendiri dan membutuhkan orang lain".

\section{Simpulan}

Berdasarkan hasil penelitian kuantitatif dan pembahasan maka dapat disimpulkan bahwa terdapat hubungan antara kecerdasan moral dengan kecerdasan sosial siswa SD kelas IV Gugus XII Kota Bengkulu. Hasil yang diperoleh dari perhitungan rhitung $(0,471)$ lebih besar daripada rtabel $(0,339)$ dengan taraf signifikan $\alpha=0,05$ dan memberikan sumbangan sebesar $22,17 \%$. Hasil perhitungan diperoleh nilai signifikan thitung $(3,019)$ lebih besar daripada tabel $(1,668)$.

Penelitian ini menunjukkan bahwa kecerdasan moral anak pada penelitian mempunyai kontribusi cukup yang berarti anak masih memiliki kecerdasan moral yang cukup atau baik terhadap orang lain. Pada indikator kecerdasan moral seperti empati dan rasa hormat masih terbilang cukup atau baik. Sedangkan indikator toleransi memperoleh korelasi tinggi. Hal ini menunjukkan bahwa anak telah memiliki toleransi terhadap orang lain seperti menghormati perbedaan agama, suku, ras, golongan dan menghargai pendapat orang lain. Anak yang memiliki kecerdasan moral yang tinggi maka akan mempunyai kecerdasan sosial yang baik. Sehingga anak tersebut mudah bergaul dengan orang lain dan tidak mudah tersisihkan dalam lingkungan sosialnya.

\section{Saran}

Guru disarankan untuk dapat mengembangkan kecerdasan moral dan kecerdasan sosial dalam pembelajaran di sekolah dengan cara mengembangkan tujuh kebajikan utama kecerdasan moral dan mengajarkan berinteraksi dengan baik terhadap orang lain.

Pada penelitian ini instrumen yang digunakan adalah angket, untuk peneliti selanjutnya dapat menggunakan penelitian eksperimen atau penelitian kualitatif.

Bagi penelitian selanjutnya, disarankan sampelnya untuk lebih besar lagi agar mendapatkan hasil penelitian korelasi yang baik atau sangat baik dalam penelitian selanjutnya.

\section{Referensi}

Azzet, M., A. 2014. Mengembangkan Kecerdasan Sosial Bagi Anak. Yogyakarta: Kata Hati. 
Borba, M. 2008. Membangun Kecerdasan Moral (Edisi ke-1) (Alih bahasa: Lina Jusuf), Jakarta: Gramedia Pustaka Utama.

Coles, R. 2003. Menumbuhkan Kecerdasan Moral Pada Anak (Alih bahasa: T. Hermaya), Jakarta: PT Gramedia Pustaka Utama.

Drajat, M. \& Effendi, R. 2014. Etika Profesi Guru. Bandung: ALFABETA.

Afrianti N. 2017. Profil Kecerdasan Sosial Siswa Sma Di Kota Bandung Sebagai Studi Awal Penyelenggaraan Layanan Bimbingan Konseling, Jurnal Ilmiah Psikologi Terapan, vol. 5, no 1, Hal:1-20.

Notosrijoedono A..A.R. 2015. Menanamkan Kecerdasan Moral Sejak Anak Usia Dini Pada Keluarga Muslim. Jurnal Tarbiyah, vol 22, no.1, Hal:1-18

News, D. 2017. "Ini Penyebab Bocah SD Tewas Usai Berkelahi dengan Teman di Bandung", https://news.detik.com/berita-jawa-barat/d-3743019/inipenyebab-bocah-sd-tewas-usai-berkelahi-dengan-teman-di-bandung.

Diunduh pada tanggal 19 Februari 2018. 